\title{
Reflexões primeiras sobre: A Teoria do Espaço Social e da Gênese do Estado de Pierre Bourdieu.*
}

\author{
Roberto Di Benedetto**
}

1. O objetivo deste artigo, fruto do estudo de algumas das obras de Pierre Bourdieu traduzidas para o português, é apontar a existência, à todos aqueles que se interessam por sociologia e sabiamente reconhecem sua importância para o estudo do Direito, do trabalho deste sociólogo considerado um dos melhores e mais brilhantes da atualidade. Seus objetos de estudo são muito variados, como também são os de Max Weber e Durkheim, cujas influências são marcantes no pensamento de Bourdieu. Suas análises percorrem desde sociedades tribais norte-africanas, ensino e movimentos estudantis franceses, até a linguagem e a arte.

Procuraremos aqui realizar apenas algumas reflexões a respeito da sua teoria de espaço social, incluindo os conceitos de habitus, campo, Estado, classe, capital, região, sendo que apenas esboçaremos as explicações a estes conceitos. É fundamental que limitemos o nosso assunto por motivos óbvios: a amplitude do seu trabalho; a falta de espaço para uma abordagem exaustiva; e a limitação deste estudante de sociologia. Este artigo é um ponto de partida, esperamos ter a oportunidade de, em outros momentos, fazer uma análise mais elaborada de importantes aspectos de seu pensamento como: a economia das trocas simbólicas (o conceito de dádiva) e lingüísticas; a análise do grau de interesse e de orientação racional da conduta dos agentes (e a influência do habitus de classe); o estudo da reprodução e conservação dos capitais (compreendendo a análise da família e do sistema escolar); a elaboração dos conceitos de campo político, e sobretudo, de campo jưrídico, a explicação de sua mecânica e lógica própria, de grande importância para nós, estudantes do direito.

* Este artigo é um dos resultados dos estudos realizados na monitoria de Direito e Sociedade A, sob a orientação do Professor Manoel Eduardo Alves Camargo e Gomes.

** Acadêmico do segundo ano de Direito da Universidade Federal do Paraná e Monitor da disciplina de Direito e Sociedade A.

Revista da Faculdade de Direito da UFPR, Curitiba, a. 29, n. 29, 1996, p. 259-264 
2.A sociedade pode ser entendida como um espaço, ${ }^{1}$ que segundo Bourdieu é um "conjunto de posições distintas e coexistentes, exteriores umas às outras, definidas umas em relação às outras por sua exterioridade mútua e por relações de proximidades, de vizinhança ou de distanciamento e, também, por relações de ordem, como acima, abaixo e entre". ${ }^{2}$ Este espaço social é organizado de acordo com a quantidade e com os tipos de capital que cada agente ou grupo social possui. Os diferentes capitais são distribuídos em uma primeira coordenada pelo volume do capital global que possuem e em uma segunda coordenada pela composição deste capital global.

A partir da noção de campo entende-se a idéia de capital, campo é um espaço de luta pela posse sobre um determinado capital e sobre o poder de impor os princípios de di-visão. ${ }^{3}$ Cada agente participa de vários campos: campo escolar, jurídico, econômico, político, artístico e possui uma certa quantidade de capital relativo a cada um deles: capital cultural (compreendendo o de informação, o escolar), capital simbólico jurídico, capital econômico, capital político (compreendendo o capital de popularidade, heróico e delegado), o capital artístico; de acordo com a qual ocupa um posição dentro da hierarquia de cada campo, o conjunto destas posições determina a posição a ser ocupada no espaço social.

Pode-se esboçar várias regiões dentro do espaço social, estas regiões são classes teóricas, "conjuntos de agentes que ocupam posições semelhantes e que, colocados em condições semelhantes e sujeitos a condicionamentos semelhantes, têm, com toda a probabilidade, atitudes e interesses semelhantes, logo, práticas e tomadas de posição semelhantes". 4 Existe um espaço objetivo que gera afinidades e afastamentos, que possui uma probabilidade de formarem grupos práticos, todavia "a aproximação dos mais chegados nunca é necessária e a aproximação dos mais afastados nunca é impossivel". Ao se organizar o espaço social, constrói-se também

1 "Realidade invisível que organiza as práticas e as representações dos agentes" Bourdieu, Razões Práticas, op. cit., p. 24

2 Bourdieu, Razões práticas, op. cit., p.18-19.

3 Os princípios de di-visão seriam os instrumentos usados pelos agentes e grupos para observar (visão) e classificar (divisão) a realidade, o mundo social. São os óculos pelos quais os agentes inseridos no espaços social vêem, analisam e concebem este espaço. São categorias mentais de percepção do mundo social, que são frutos da incorporação das estruturas objetivas do espaço social.

4 Bourdieu, O poder simbólico, op. cit., p. 136.

5 Bourdieu, O poder simbólico, op. cit., p. 137 
classes teóricas, fictícias, que não são grupos reais, não existem na realidade. Essa construção teórica vaticina relações entre as pessoas, pois a proximidade no espaço social significa uma afinidade de habitus, escolhas, igualdade de bens e maior probabilidade de encontros (excluindo os encontros que violam as fronteiras sociais). Estas classes teóricas, apesar de não constituírem classes no sentido marxista (grupos unidos por objetivos comuns contra uma outra classe ou grupos mobilizados por uma luta), devido a proximidade no espaço social, guardam uma pretensão de existir, uma possibilidade de se transformarem, através de uma mobilização política, em classes marxistas, são classes prováveis. ${ }^{6}$

A cada região vai corresponder um habitus gerado pela posição ocupada e identificador desta posição. O habitus é produto das posições, é diferenciado e diferenciador, gera práticas distintas e distintivas, é princípio de classificação, é o "princípio gerador e unificador que retraduz as características intrínsecas e relacionais de uma posição em um estilo de vida unívoco, isto é, em um conjunto unívoco de escolhas de pessoas, de bens, de práticas". 7 Estes ao serem percebidos tornam-se signos distintivos, diferenças simbólicas e componentes de sistemas simbólicos. A distinção, que pode-se encontrar entre agentes e grupos, é uma propriedade relacional, isto é, apenas existe em relação a outras, ${ }^{8}$ ela encerra as idéias de diferença, separação. Outro equívoco que deve ser evitado é transformar as propriedades (habitus e escolhas) de uma certa posição social, de um grupo, em dado momento e local, em propriedades necessárias e intrínsecas.

3. Todos os agentes e grupos sociais lutam para imporem os princípios de di-visão. Para compreendermos um pouco melhor este outro conceito basilar de Bourdieu, é preciso entrar em seu estudo sobre a formação e o surgimento do Estado.

O Estado cria e impõe os meios de di-visão, pelos quais se observa e se entende todas as coisas e o próprio Estado. Logo, ele pensa até por quem procura pensá-lo, a grande maioria dos estudos sobre ele,

6 O erro de Marx foi não usar o efeito teoria (quer dizer, ver uma realidade que não existe por não ser (re)conhecida), efeito teorizado por ele, porém não usado em sua teoria. O que existem são diferenças, e não classes sociais. "O que existe é um espaço social, um espaço de diferenças, no qual as classes existem de algum modo em estado virtual, pontilhadas, não como um dado, mas como algo que se trata de fazer." Bourdieu, Razões práticas, op. cit., p. 27.

7 Bourdieu, Razões práticas, op. cit., p. 21-22.

8 cf. noção de espaço já explicada acima. 
participaram e influenciaram na sua construção e consolidação, isto é, estão intimamente conectado à sua existência, e são na verdade diretrizes políticas dos dominantes que pretendem impor sua concepção de Estado.

Com base em Weber, que define o Estado como uma comunidade humana que pretende, com êxito, o monopólio do uso legítimo da força física dentro de um determinado território. Bourdieu diz que: "O Estado é um $x$ (a ser determinado) que reivindica com sucesso o monopólio do uso legítimo da violência física e simbólica em um território determinado e sobre o conjunto da população correspondente". 9

A violência simbólica é exercida pelo Estado, porque este está institucionalizado objetiva (nas estruturas sociais) e subjetivamente (nas estruturas mentais), deste modo seu processo histórico de institucionalização é esquecido e ele assume aparência natural. Reconstruir a sua gênese é o melhor meio de romper com a ordem estabelecida.

O Estado resulta da concentração de diversos tipos de capital: econômico, cultural (de informação), simbólico, de instrumentos de coerção (de força física). Assim, o Estado transforma-se em "detentor de uma espécie de metacapital, com poder sobre os outros tipos de capital e sobre seus detentores". ${ }^{10}$ O metacapital ou capital estatal, fruto do processo de concentração, confere ao Estado poder sobre os campos, os capitais e as taxas de câmbio entre eles. Logo, com o Estado constrói-se o Campo do Poder: "espaço de jogo no interior do qual os detentores de capital (de diferentes tipos) lutam particularmente pelo poder sobre o Estado". 11

O Estado concentra o capital de força física, restringindo o poder de aplicar a violência física a um grupo especializado separado da sociedade comum, isso se faz pela unificação do espaço econômico e pela criação de um erário eficaz. O imposto transforma o capital econômico em capital simbólico para o príncipe, ele sustenta as forças armadas, que ampliam e defendem o território, mas também asseguram o seu pagamento (causalidade circular).

Junto com a concentração do capital econômico, promove-se a concentração do capital de informação: recenseamento, contabilidade do

9 Bourdieu, Razões práticas, op. cit., p. 97.

10 Bourdieu, Razões práticas, op. cit., p. 99.

11 Bourdieu, Razões práticas, op. cit., p. 100. 
físco, cartografia, arquivos, unificação dos códigos jurídicos, lingüístico, métrico, além da uniformização das estruturas burocráticas, escolares, do direito e dos rituais sociais. O Estado concentra a informação, a analisa e a redistribui, e porque a cultura é unificadora, ele cria e impõe os princípios de di-visão comuns a todo o território, isso levará ao surgimento da identidade da nação. Tal unificação cultural e lingüística somada a concentração das forças armadas e dos impostos (necessária para a concentração do capital simbólico de reconhecimento - legitimidade -), levam à obrigatoriedade da cultura dominante (legítima) e ao desprezo pelas demais culturas e línguas, além de originarem o nacionalismo, solidificarem a unificação dó território e desenvolverem uma instância de soberania estatal.

O capital simbólico também se concentra com a unificação do capital jurídico (capital simbólico objetivado e codificado) e formação de um campo jurídico independente; e com a transformação do Estado em "instância central de nomeação". O capital simbólico da nobreza é objetivado, codificado, burocratizado e ao lado da distinção natural, difusa, hereditária e socialmente reconhecida da nobreza, surge o enobrecimento legal pelo Estado.

O capital simbólico é um capital qualquer reconhecido, através dos princípios de di-visão, por todo o espaço social, que lhe confere valor. Sendo que o Estado é quem impõe tais modos de di-visão, é ele que concentra e exerce o poder simbólico, logo o modo dos agentes de verem o mundo é fruto da estrutura do grupo ao qual pertencem. Aquela imposição estatal gera estruturas cognitivas e de avaliação do mundo semelhantes, gerando um "conformismo lógico e moral", ou ainda, um habitus comum. A imposição dos princípios de di-visão é essencial para a dominação simbólica do Estado.

Kant diz que as estruturas de conhecimento são formas da razão, porém elas são imposição do detentor do poder simbólico e deste modo estão de acordo com as estruturas objetivas do mundo social, logo, deve-se buscar no estruturalismo os instrumentos para ver os fatos simbólicos como sistemas. A legitimidade vem desta estrutura incorporada no inconsciente, além das estruturas objetivas. Isso explica a facilidade com que os agentes são manipulados pelos dominantes. 
A monopolização realizada pelo Estado, esta intimamente ligada à luta pelo monopólio deste monopólio (campo do poder), isto é, pela exclusividade de impor os seus princípios de di-visão, ou ainda, pela posse do capital estatal (metacapital).

4.Em suma, segundo Bourdieu, a sociedade é um espaço, no qual estão distribuídos os agentes de acordo com as suas posições nos vários campos, quer dizer, de acordo com o volume do seu capital global e da composição deste capital. Neste espaço podemos identificar regiões que são classes teóricas (prováveis), a cada uma destas regiões corresponde um habitus (idiossincrasias) criado por ela e seu identificador. Estes agentes, portadores de diferentes quantidades e qualidades de capital, lutam para imporem seus princípios de di-visão, ou seja, lutam (dentro do campo do poder) para possuírem o capital estatal que é o metacapital, e deste modo possuírem poder sobre os demais capitais e sobre as taxas de troca entre eles.

\section{Referências bibliográficas:}

BOURDIEU, Pierre. A Economia das Trocas Lingüisticas: O que falar quer dizer. São Paulo: Edusp, 1996. 192 p.

. A economia das trocas simbólicas. $3^{\mathrm{a}}$ ed. Org. Sergio Miceli. São Paulo: Perspectiva, 1992. 367 p.

. O poder simbólico. Trad. Fernando Tomaz. Rio de Janeiro: Bertrand Brasil, 1989. 322 p.

Razões práticas: Sobre a teoria da ação. Trad. Mariza Corrêa. Campinas: Papirus, 1996. 232 p.

Sociologia. 2a ed. Org. Renato Ortiz. Coordenador: Florestan Fernandes. São Paulo: Ática, 1994. 191 p. 